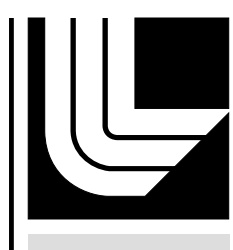

LAW RENCE LIVERMORE N A T IO N A L LABORATORY

LLNL Experiments at OMEGA in FY05

R. E. Turner

October 17, 2005 
This document was prepared as an account of work sponsored by an agency of the United States Government. Neither the United States Government nor the University of California nor any of their employees, makes any warranty, express or implied, or assumes any legal liability or responsibility for the accuracy, completeness, or usefulness of any information, apparatus, product, or process disclosed, or represents that its use would not infringe privately owned rights. Reference herein to any specific commercial product, process, or service by trade name, trademark, manufacturer, or otherwise, does not necessarily constitute or imply its endorsement, recommendation, or favoring by the United States Government or the University of California. The views and opinions of authors expressed herein do not necessarily state or reflect those of the United States Government or the University of California, and shall not be used for advertising or product endorsement purposes.

This work was performed under the auspices of the U.S. Department of Energy by University of California, Lawrence Livermore National Laboratory under Contract W-7405-Eng-48. 


\section{LLNL experiments at OMEGA in FY05}

During FY05, LLNL was scheduled for 372 shots on Omega. These were distributed into 191 planned shots for the Inertial Confinement Fusion (ICF) program, and 181 planned shots for the High Energy Density Sciences (HEDS) program. The actual Omega performance averaged $6 \%$ more shots than scheduled. A brief summary of the various campaigns follows, starting with HEDS experiments.

The Hot Hohlraum experiments were devoted to exploring the laser-plasma interaction limits of very small half-hohlraums ('halfraums'), and maximizing the effective radiation temperatures obtained. Figure [LLNL-1] shows X-ray images recorded at various times and photon energies, which show the hohlraum filling to over-critical densities.

Hohlraum Development experiments substituted high Z foam (approximately 5\% of solid density) for solid gold, for the hohlraum wall, and attempted to measure a predicted increase in x-ray conversion efficiency.

Pushered Single Shell experiments used a glass capsule, coated with a plastic ablator, to explore physics issues associated with double-shell capsules.

Isentropic Compression experiments used a carefully shaped laser pulse to create a smoothly increasing, shockless compression of various target materials, for equation of state measurements. These included diffraction experiments, where x-ray diffraction from crystalline materials was used to diagnose change of state. Low temperature RayleighTaylor experiments also used the isentropic drive, to look at the hydrodynamic stability of solid materials under strong acceleration.

Backlighter capability experiments were conducted, with the aim of improving our x-ray backlighting capabilities. These experiments included backlit pinholes, for point-projection measurements, as well as various mid-Z (e.g., Ti) doped foams for increased $\mathrm{x}$-ray conversion efficiency into multi-keV photons.

Radiation flow experiments continued from the previous year. These experiments used foam-filled hohlraums to measure $\mathrm{x}$-ray propagation through various low density materials.

NWET (effects test) concentrated on fielding multiple diagnostics to measure electromagnet pulse, and x-rays, from laser driven hohlraums filled with low density, mid-Z foams. These experiments were a collaboration between LLNL, LLE, and NRL, requiring extensive installation of specialized diagnostics. Figure [LLNL-2] shows the $x-$ ray spectra recorded from $5 \mathrm{mg} / \mathrm{cc}$ aerogel (silicon dioxide) foam, doped with 20 atom-\% Ge.

Such targets obtained an overall conversion efficiency of order $0.3 \%$ into x-rays in the 9.4 to $13.8 \mathrm{keV}$ range. 
An extensive Opacity campaign was conducted on Omega. Early experiments were dedicated to developing appropriate x-ray backlighting sources, leading up to future measurements of the opacity of warm materials.

Planar Double shell experiments were carried out to look at the effects of x-ray preheat on the inner shell of a double shell capsule, using a planar geometry which allowed diagnostic access.

DDP experiments looked at jets of material driven into foams with varying cell sizes. X-ray backlighting was used to measure the propagation of the jets into the foams.

The first ICF experiments of the year looked at the laser-plasma issues, and x-ray drive measurements, of hohlraums with low and mid- $Z$ liners, and foam fills. These liners and foams are designed to inhibit inward motion of the hohlraum walls, and are an alternative to gas-filled designs.

We also began a campaign to look at the effects of fill tubes on capsules. These indirectly driven capsules used a single perturbation on the surface of the capsule to simulate, in a calculable way, the effect of an actual fill tube on the hydrodynamic stability of the shell. Figure [LLNL-3] shows high magnification x-ray images of such targets. The perturbation has grown, and produced a jet of mid-Z material (which was originally implanted in the inner wall of the capsule). This material becomes visible in $\mathrm{x}-$ ray wavelengths as it is heated by the hot core.

Gas-Hydro experiments used large, plastic, gas-filled hohlraums, with a foam ball at the center. The objective was to reduce the x-ray drive, so that the direct, hydrodynamic effects of the laser-heated fill gas on a capsule could be observed and compared with simulations. Figure [LLNL-4] shows the results of the first of such attempts. The shock front in the foam surrogate target, observed with x-ray backlighting, shows the effects of the laser-heated gas pressure, for low initial fill-pressures. However, contrary to simulations, no effect was observed at higher initial fill pressures. A new experiment will explore these issues with reduced sensitivity to target alignment.

$\mathrm{RT}(\mathrm{Be} / \mathrm{CH})$ experiments were done to develop a platform for accurately measuring the Rayleigh-Taylor growth rate of $\mathrm{Be}$, and $\mathrm{Be}$ doped with $\mathrm{Cu}$, ablators, in direct comparison with more traditional $\mathrm{CH}$ ablators.

HEP-4 implosions are a series of integrated experiments, using standardized hohlraums and laser pulseshapes while varying the surface finish of the capsules by deliberately roughening them. The resulting neutron yields are compared to simulations with capsule-fuel mix models; the initial, measured capsule perturbation spectrum is included in the simulation for each capsule, to enable direct comparison with the experimental results. These experiments have been on-going for some time, and were finished this year. Results are shown in figure [LLNL-5] 
Cocktail experiments were measurements of the effective x-ray drive power in hohlraums made of a mixture of high $\mathrm{Z}$ materials (typically $\mathrm{Au}, \mathrm{Dy}, \mathrm{U}$ ), in contrast to a single material. This year considerable R\&D from target fabrication at LLNL and GAwas applied to reduce the impurity level of oxides in these targets, leading to measured unambiguous expected increases in $\mathrm{x}$-ray flux.Figure [LLNL-6]

A week of experiments was done with beam 25 converted to $2 \omega(530 \mathrm{~nm})$. Measurements of laser-plasma interaction physics with "green" light were done in both hohlraum and open (using gas-bag targets) geometry. Figure [LLNL-7] shows measurements from a $2 \omega$ beam which was propagated axially along a laser-heated hohlraum. Measurements of transmission and stimulated backscatter are shown. In addition, experiments were done with half-hohlraums, to measure the overall x-ray conversion efficiency of $2 \omega$ light in direct, simultaneous comparison to the efficiency when using $3 \omega$ light typical of Omega.

After encouraging laser-plasma interaction physics were obtained from $\mathrm{SiO}_{2}$ foam-filled hohlraums, a series of foam-filled hohlraums with implosion capsules inside them were shot ("Plan B"). These yielded results similar to traditional vacuum hohlraums, indicating little or no deleterious effects on the x-ray drive for ICF-relevant foam fills.

X-ray scattering experiments were done, showing expected spectral features after scattering a strong line source from the hot plasma. The data were used to infer an electron temperature in the plasma.

A week of experiments was done with beam 25 converted to $4 \omega(260 \mathrm{~nm})$. The principal focus was using the $4 \omega$ light for Thomson scattering measurements. Numerous improvements were made to the diagnostics from previous experiments, and the resulting data was of high quality, enabling measurement of the electron temperature immediately external to a hohlraum laser entrance hole, and from within a hohlraum. Figure [LLNL-8] shows the Thomson-scattering derived electron temperature from within a gas-filled hohlraum, for three different laser energies. Careful characterization of these hohlraums is preliminary to their future use for LPI studies. 


\section{Fig LLNL-1}

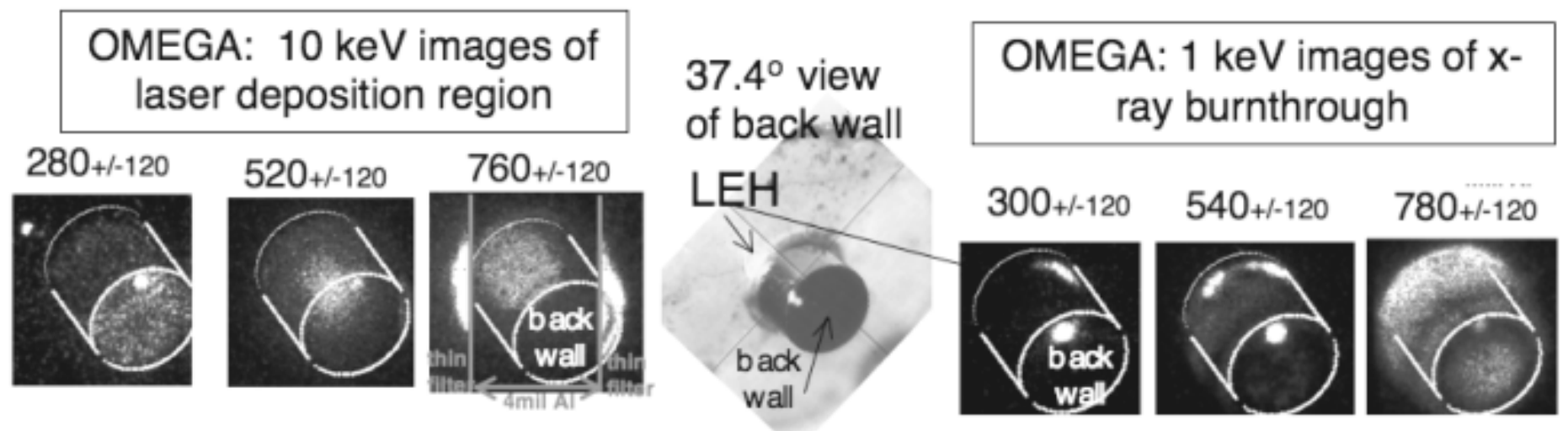




\section{Fig LLNL-2}

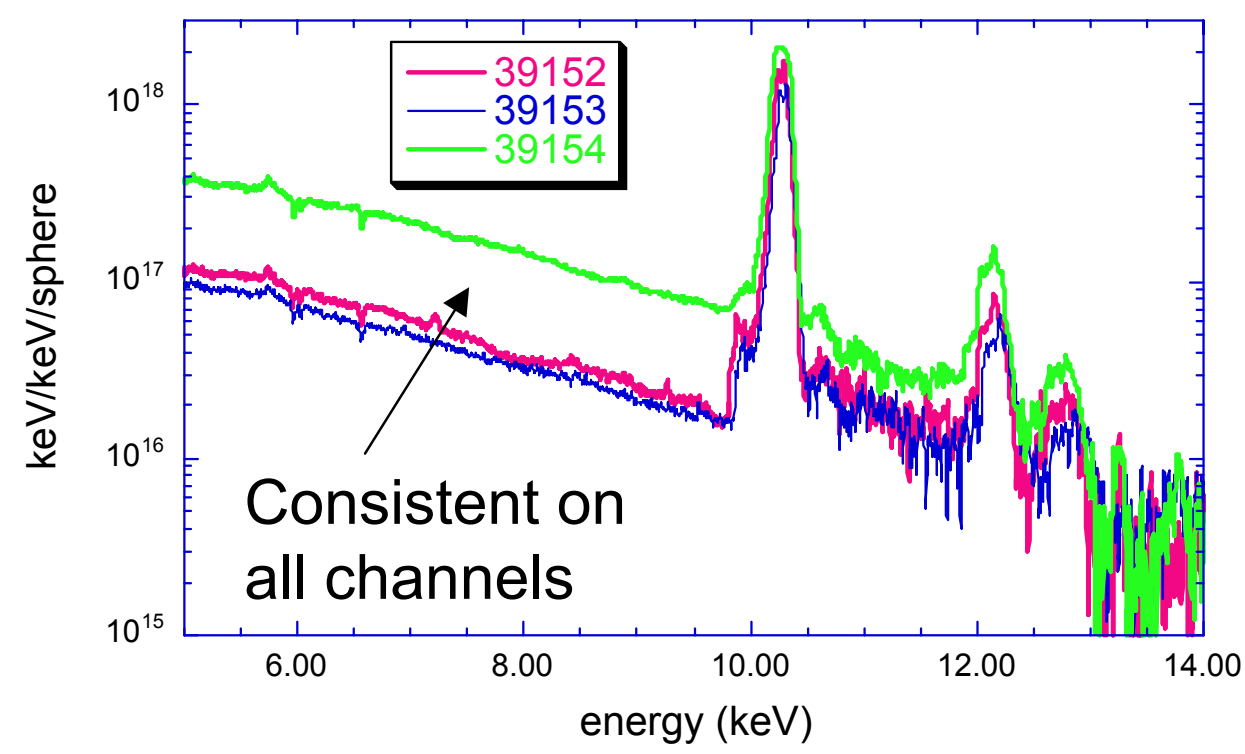

39154 - high background level, but very high signal level.

Continua from $12 \mu \mathrm{m} \mathrm{Al}+1$ mil Be strips $\rightarrow \mathrm{T}_{\mathrm{e}}$ between $2.5-2.8 \mathrm{keV}$.

39156 - high signal level for $\mathrm{He}_{\beta}, \mathrm{He}_{\gamma}$ Continua features are due to the $12.6 \mu \mathrm{m} \mathrm{Fe}$ foil transmission function. $\mathrm{T}_{\mathrm{e}}$ estimates between $2.0-2.4 \mathrm{keV}$.

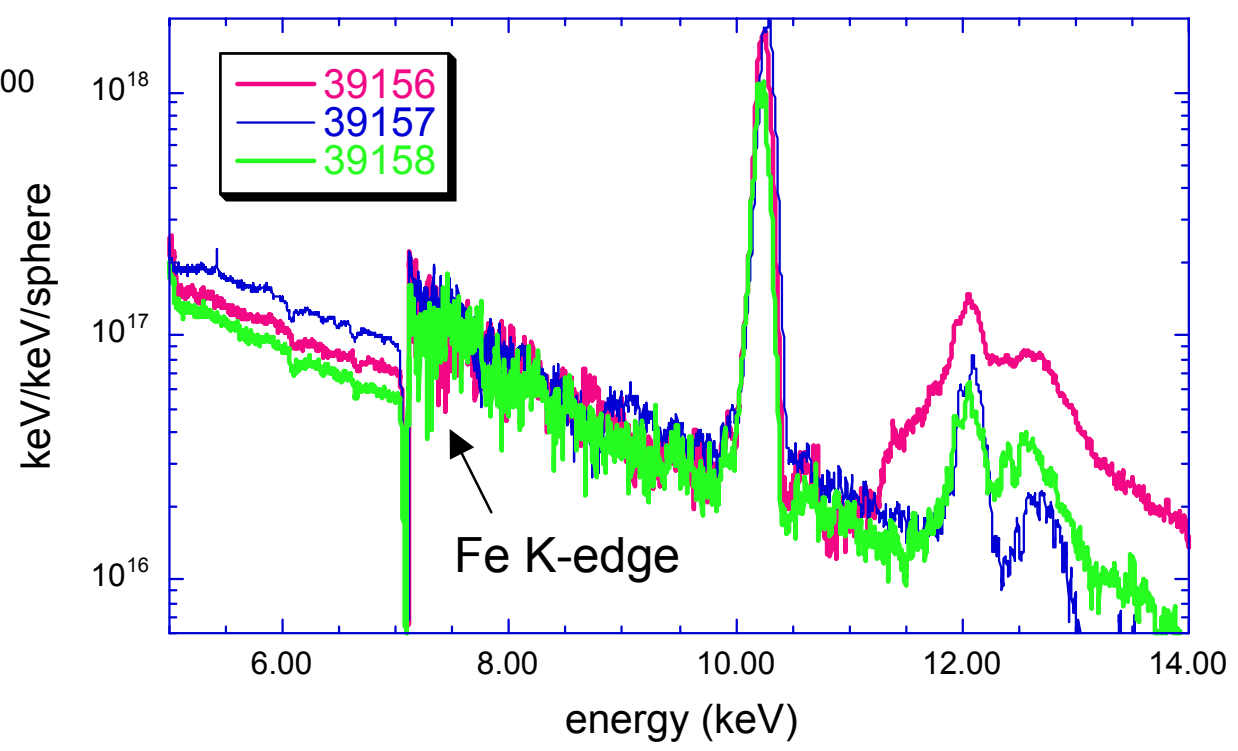


We observed evolving hydrodynamic jets

Fig LLNL-3 caused by large bumps (down to $7 \mathrm{ncc}$ ).
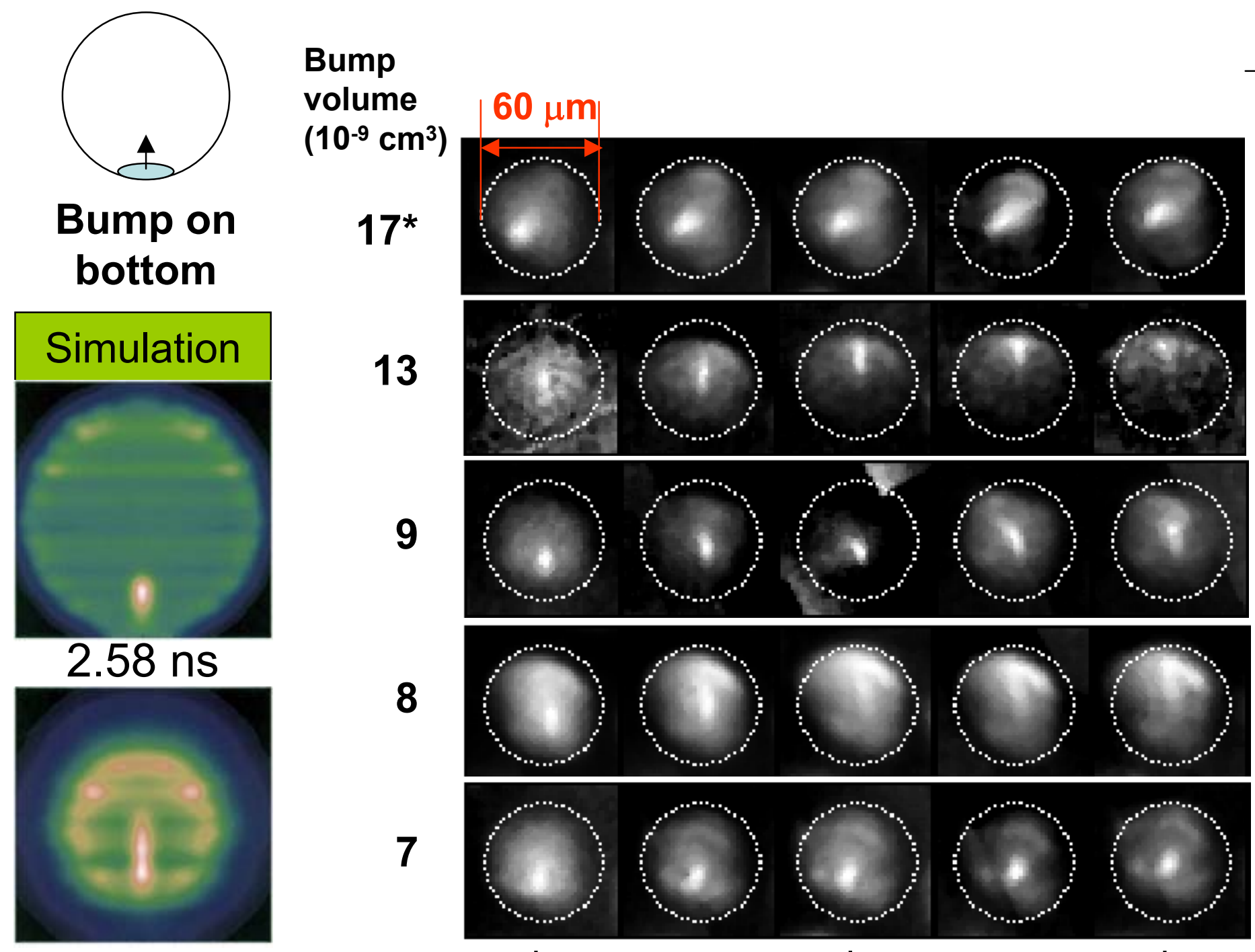

$\frac{\text { height }(\mu \mathrm{m})}{\text { Diameter }(\mu \mathrm{m})}$

$\left(10^{-9} \mathrm{~cm}^{3}\right)$

Diameter $(\mu \mathrm{m})$

$11 / 45$

(chipped bump)

13

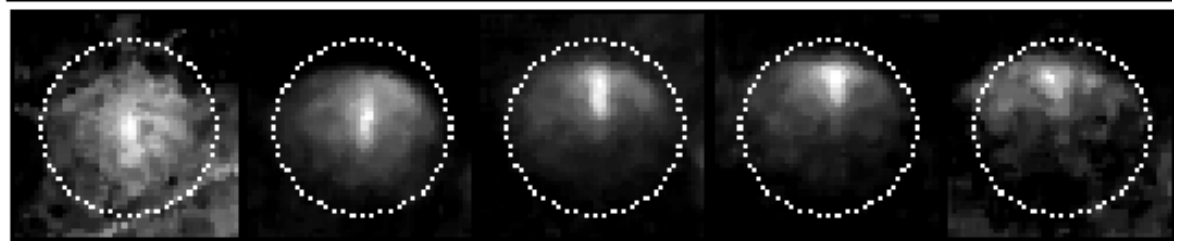

7.6 / 46

9

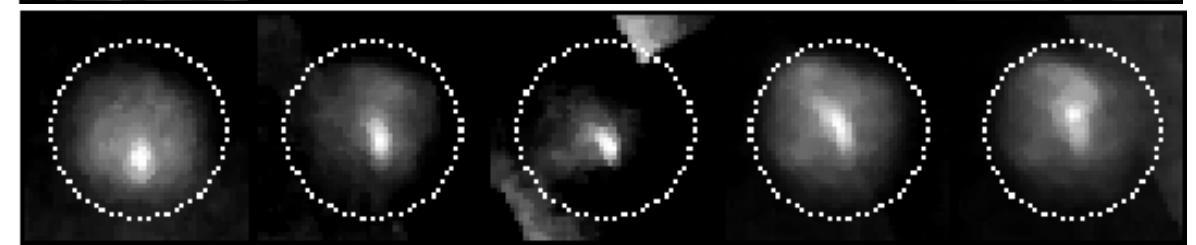

$4.5 / 51$

$2.7 \mathrm{~ns}$

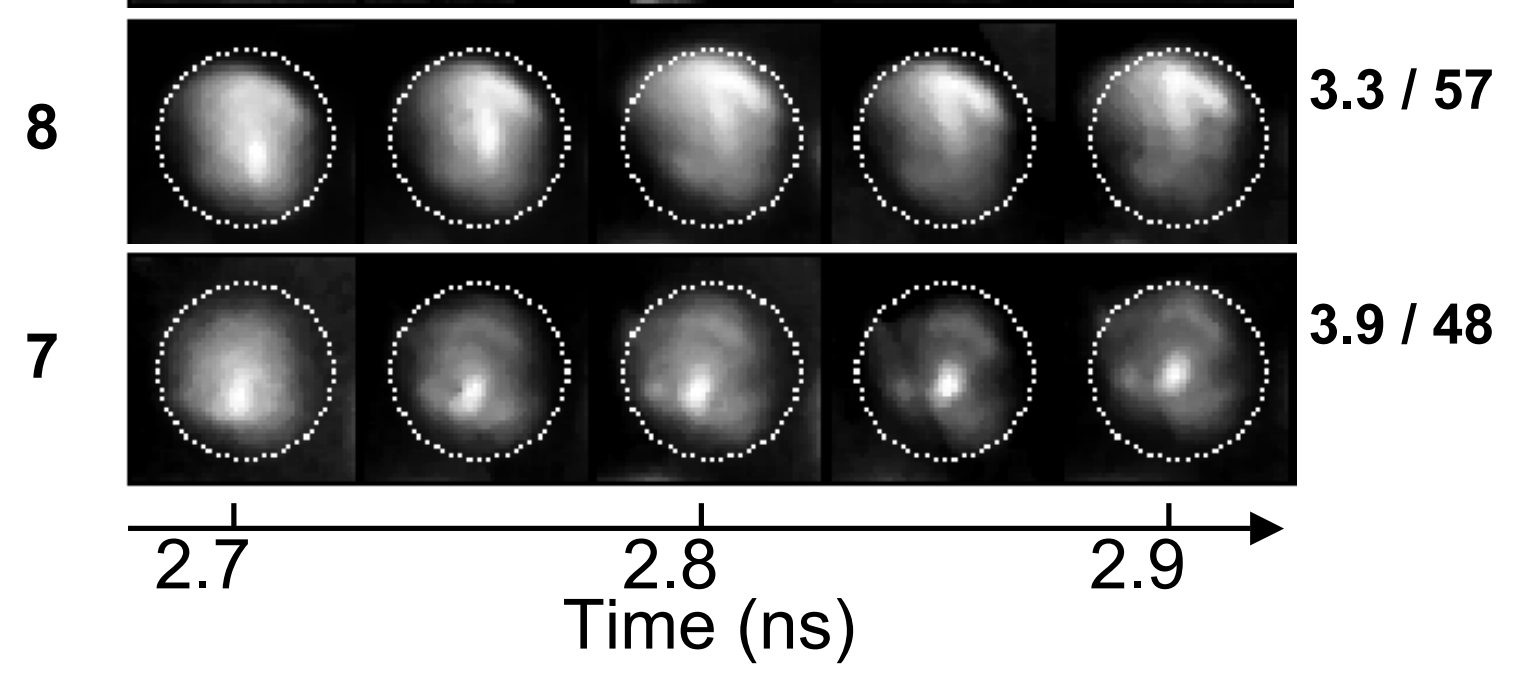


Onset of HC was measured and predicted at low fill density but not observed at high density

Fig 4

2d LASNEX predictions: $-0-0.3 \mathrm{mg} / \mathrm{cc}^{-} \mathrm{CH}_{4}$ : negligible $\mathrm{HC}$

$\cdots \odot$

- 0.5-1 $\mathrm{mg} / \mathrm{cc}$ onset of HC in the backlit observation window (5.6-9.2 ns)

- >1 mg/cc: insufficient time for HC shock to propagate in observation window

- $0.47 \mathrm{mg} / \mathrm{cc}$ : onset of HC late in time was measured and predicted

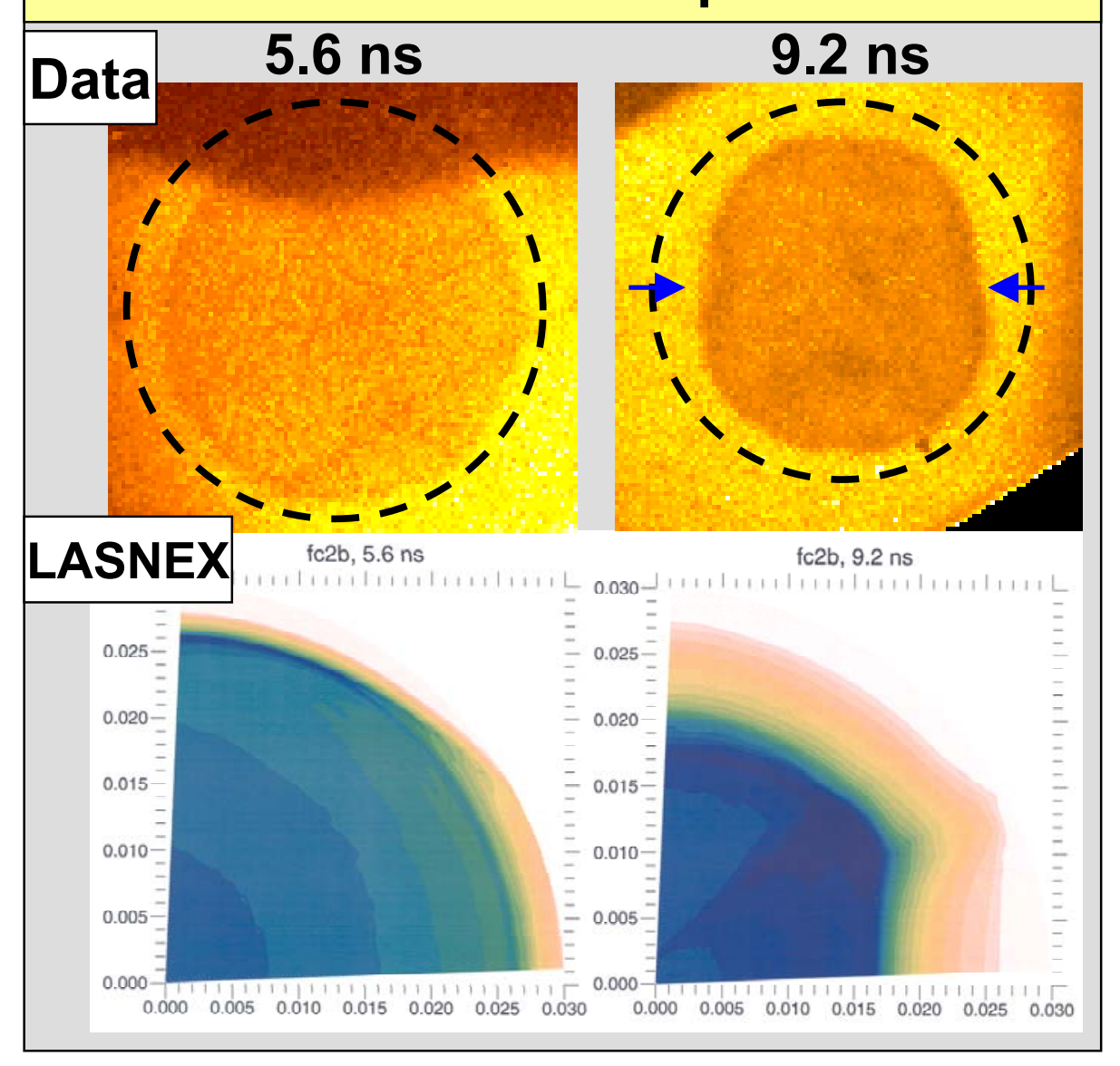

- $0.77 \mathrm{mg} / \mathrm{cc}$ : onset of HC was predicted, but not measured

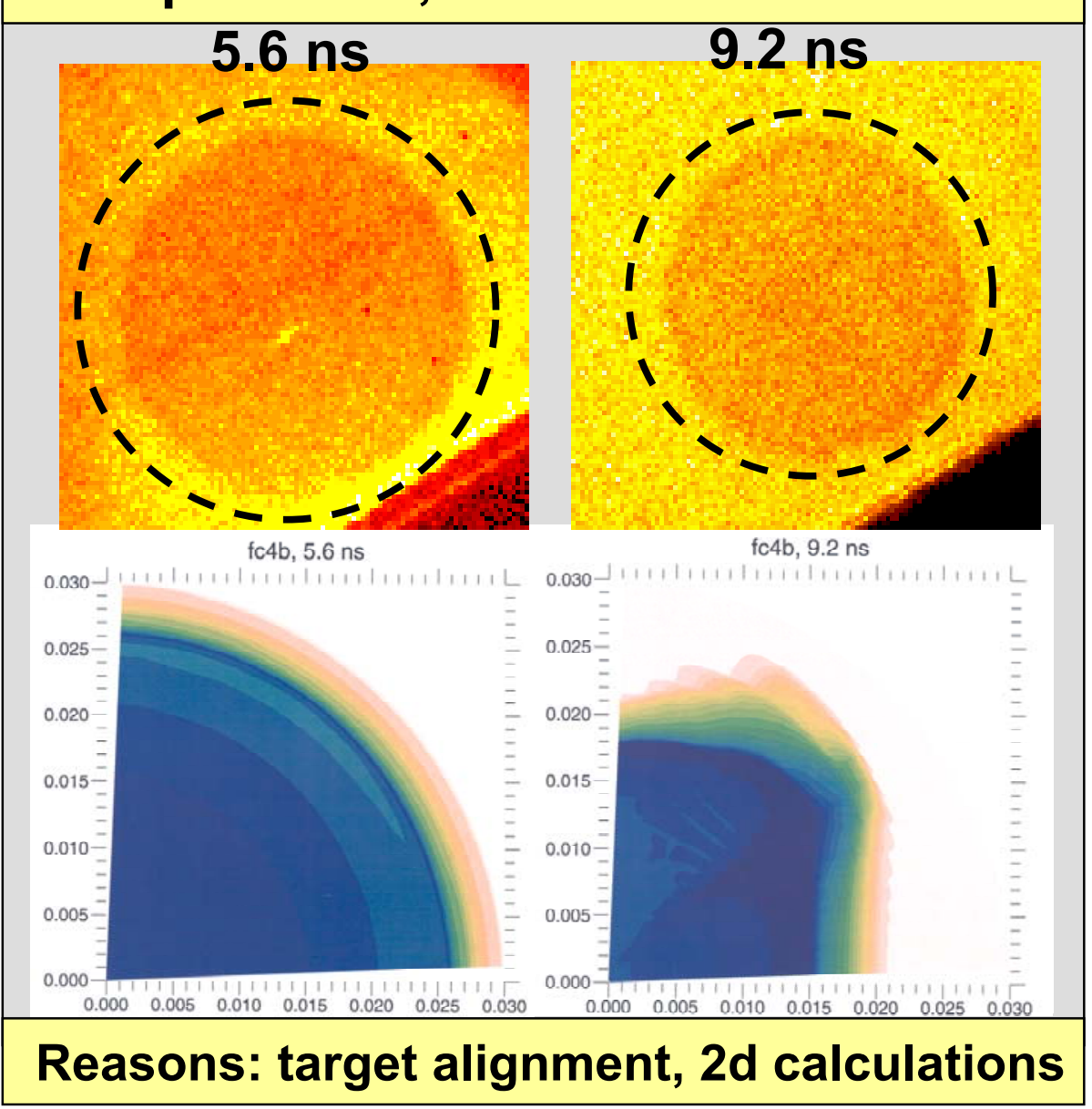




\section{We now have a complete data set for comparison to simulations}

Fig 5

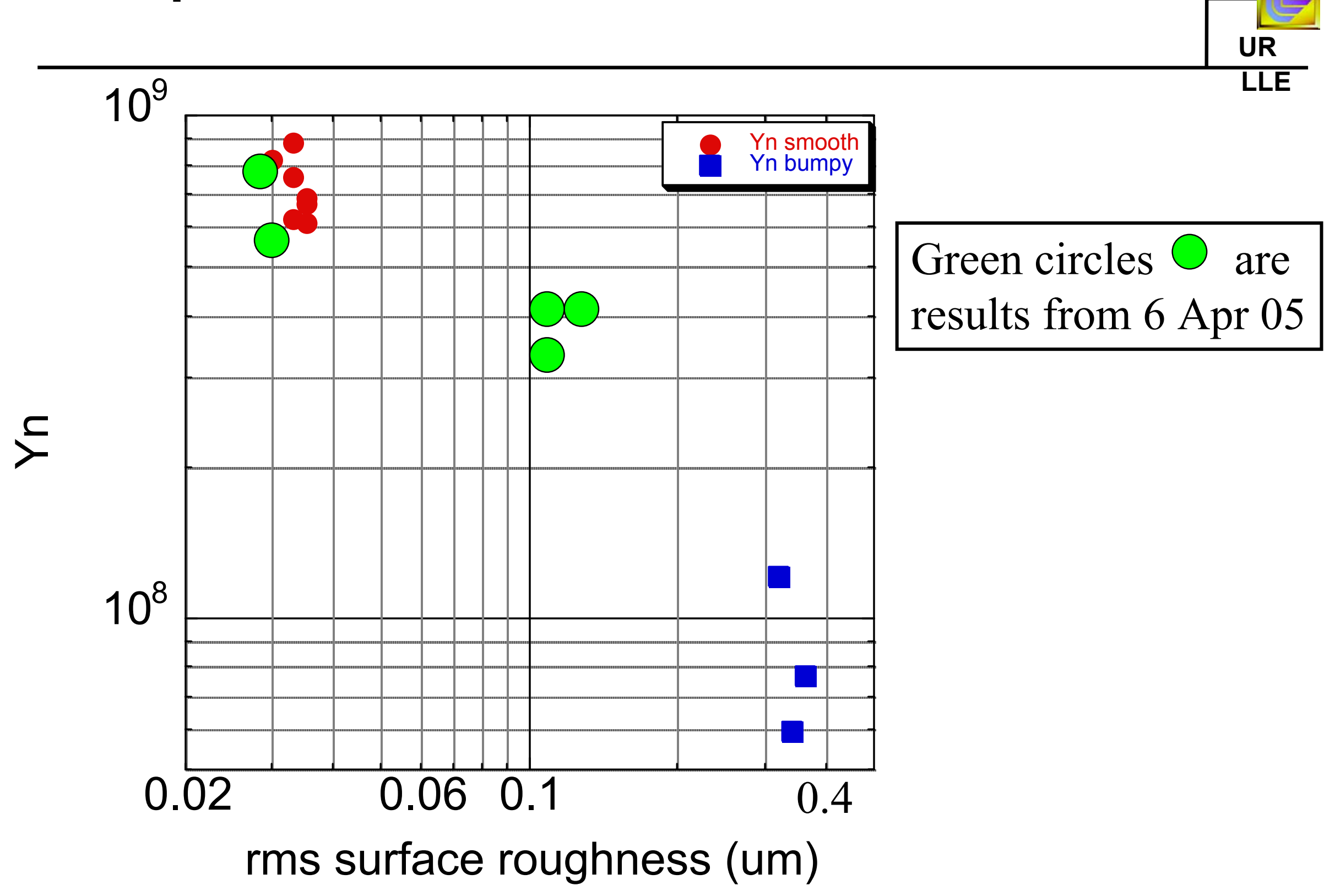


Cocktail hohlraums show expected increase in radiation flux

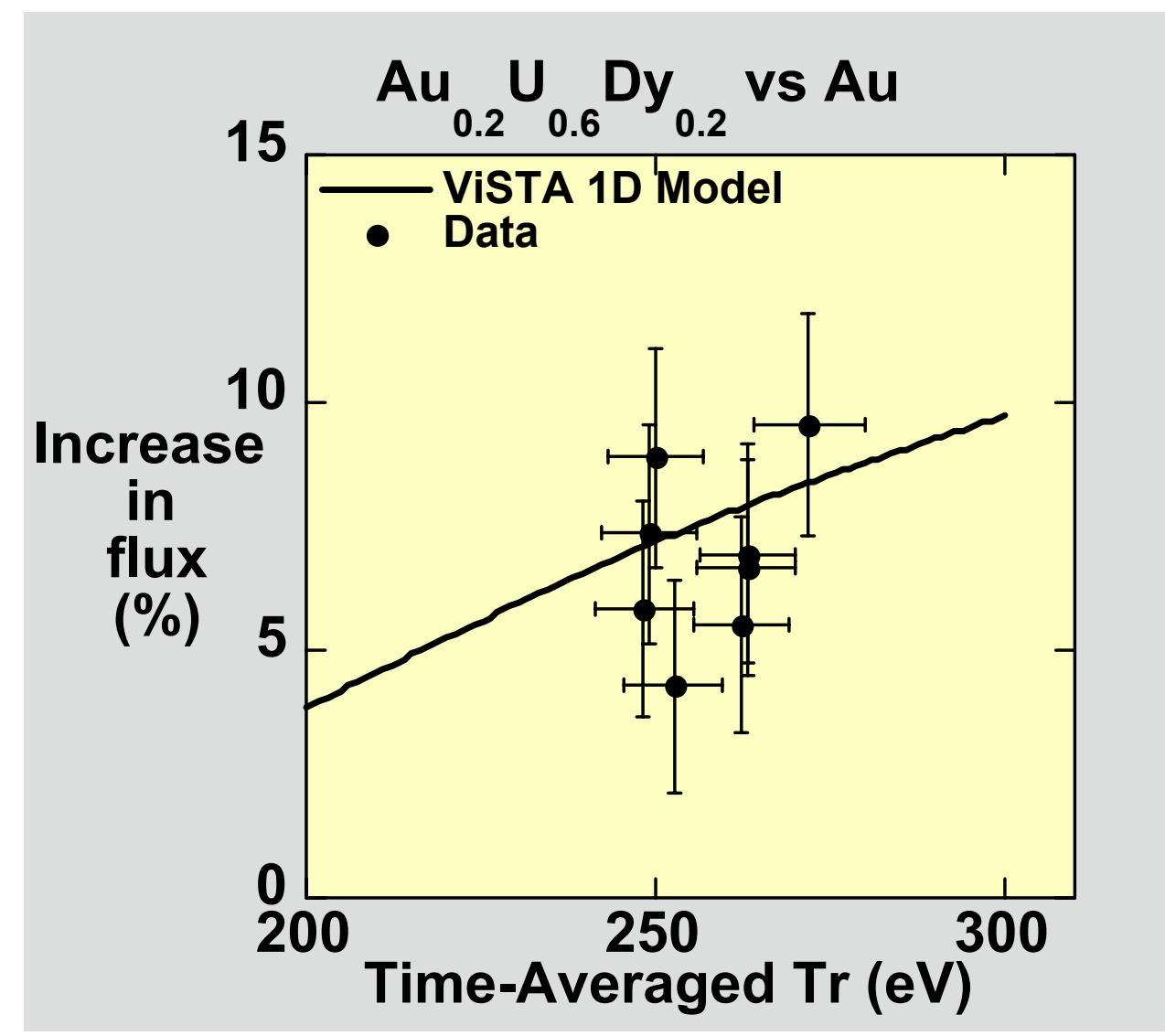


We observe a transmission of $\mathbf{8 0} \%$ for NIF-design $\quad$ Fig 6 Intensities at $\mathrm{T}_{\mathrm{e}}=3.5 \mathrm{keV}$
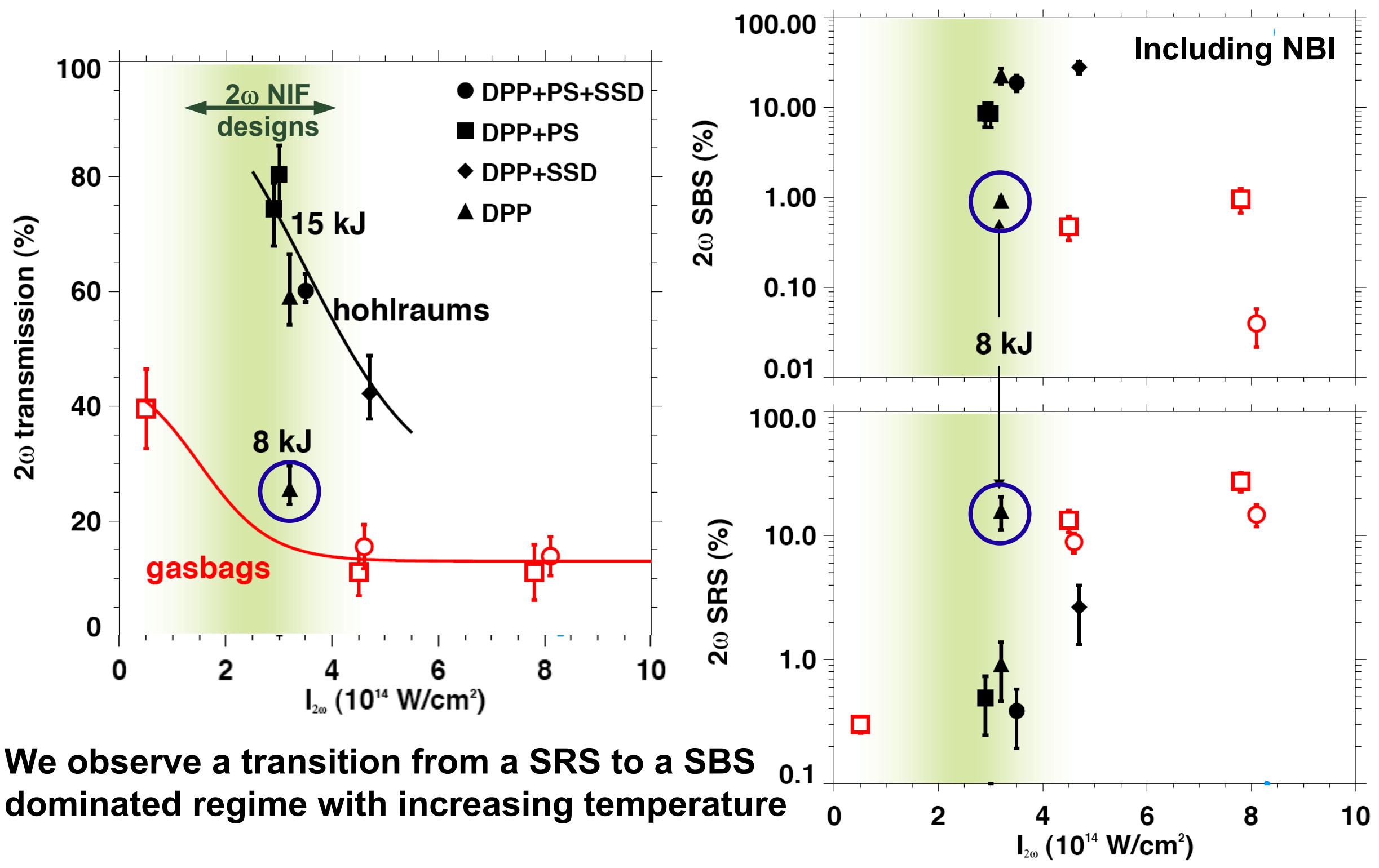

We observe a transition from a SRS to a SBS 0.1 dominated regime with increasing temperature 
Thomson scattering results show high electron temperatures
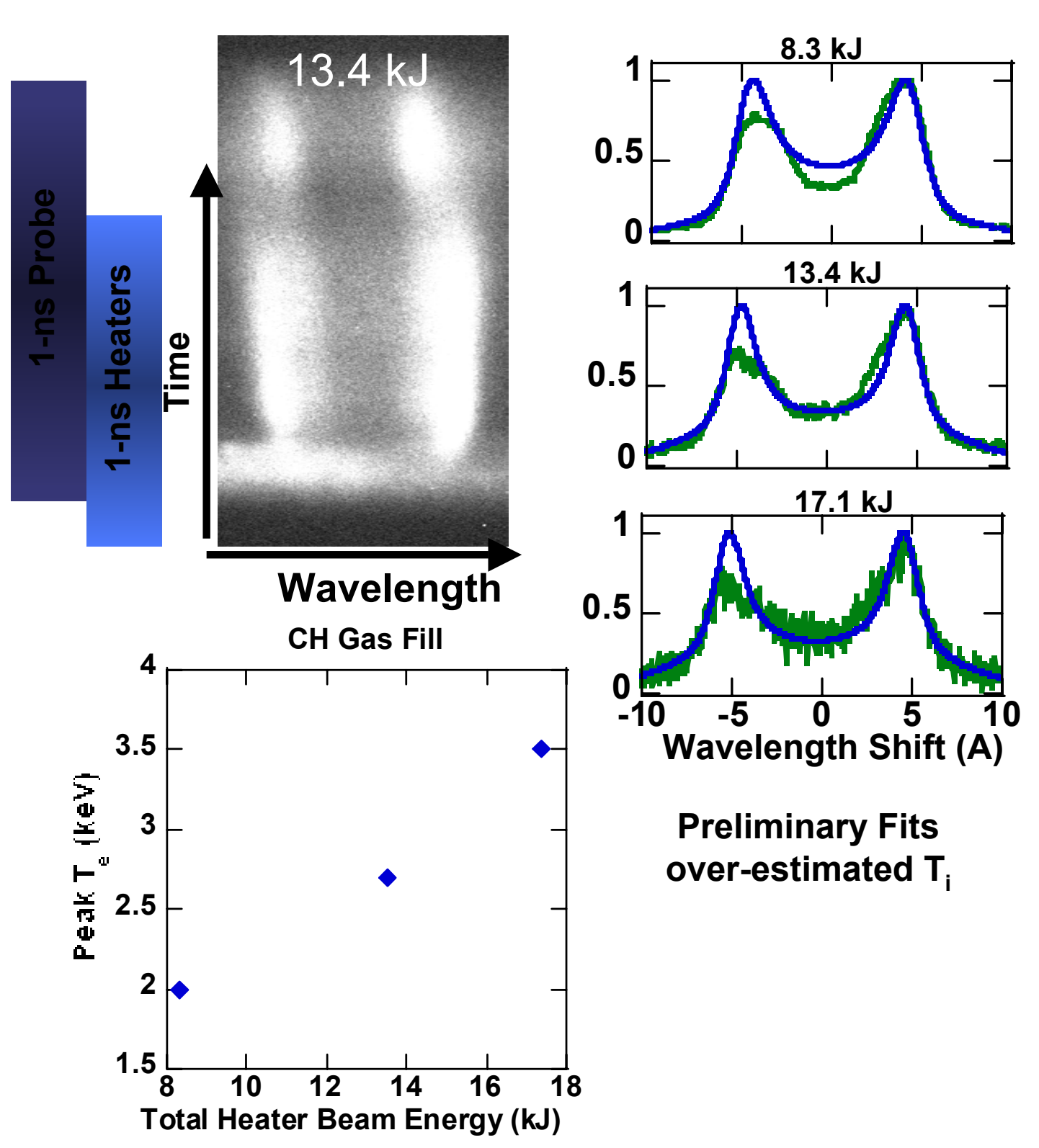

Fig 7

LASNEX predicts Hohlraum temperatures of $3.5 \mathrm{keV}$ $2 \mathrm{~mm} \times \varnothing 1.6 \mathrm{~mm}, 800 \mu \mathrm{m} \mathrm{LEH}$

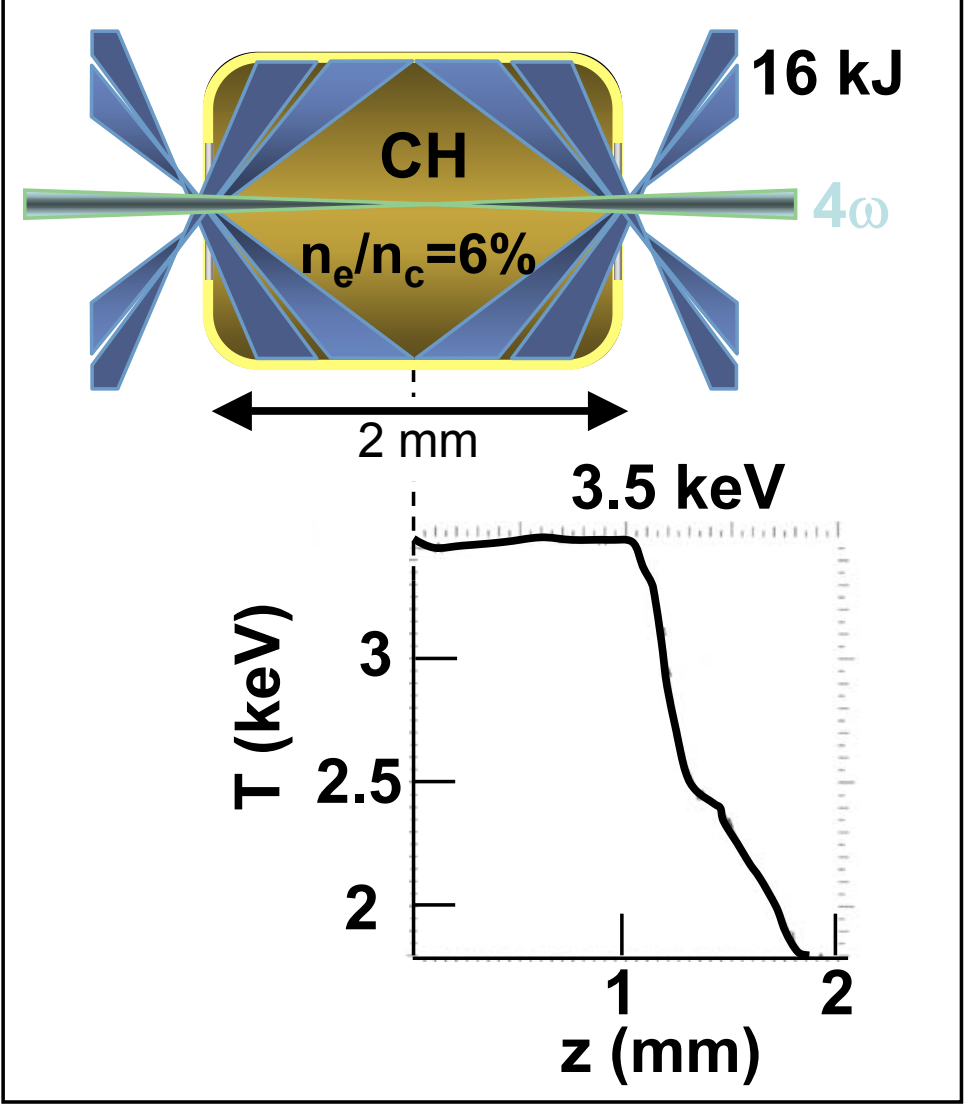

